\title{
THE MODEL OF EXTRACURRICULAR WORK WITH STUDENTS OF ENGINEERING SPECIALTIES
}

\author{
Valerii Vodovozov \\ Tallinn University of Technology, Tallinn, Estonia \\ valery.vodovozov@ttu.ee \\ Zoia Raud \\ Tallinn University of Technology, Tallinn, Estonia \\ zoja.raud@ttu.ee \\ Tetiana Detsiuk \\ Chernihiv National University of Technology, Chernihiv, Ukraine \\ tdetsiuk@gmail.com
}

\begin{abstract}
The subject of the research is the analysis of the development experience and the first phase of implementation of the model of extracurricular work with students of engineering specialties at Chernihiv National University of Technology (Ukraine), which was developed on the basis of the author's methodology ALM (active learning methods) at Tallinn University of Technology (Estonia) in combination with forms and methods of extracurricular work. The purpose of this model is to promote the enhancement of the motivation of students in engineering specialities to succeed in learning. The main task of the research is to evaluate the readiness of students of engineering specialities to participate in extracurricular activities and their awareness of the forms and methods of extracurricular work, the analysis of the first results of the implementation of the model of extracurricular work of students of engineering specialities. For the observing stage of the experiment, such methods were used as theoretical, empirical, pedagogical experiment, mathematical and statistical methods. Participants were 92 students of the 3rd year of engineering specialities of Chernihiv National University of Technology. Most students (82\%) believe that extracurricular work has an impact on the formation of the individual and on the professional growth of a future specialist. The motivation for success among most respondents (73\%) is average, $33 \%$ of respondents are not very good interlocutors who have shortcomings in communication; $60 \%$ have an average level of communication skills, $58 \%$ of respondents need to build self-confidence. Based on the received results from the questionnaire and tests carried out among students, a model of extracurricular work with students of engineering specialities has been developed. The first stage of the implementation of this model has shown a positive dynamics. The model requires further testing and research of the impact on the students'personality.
\end{abstract}

Keywords: active learning methods; educational technologies; educational activity; students of engineering specialities; extracurricular work.

\section{Introduction}

Nowadays, one of the drawbacks of academic education is the decline in the number of students studying and graduating from engineering specialities. The rapid pace of development of science and technology, in connection with the concept of sustainable development, encourages European countries to support engineering specialties in the form of scholarships, budget places, internships etc. However, the popularity of engineering specialities in recent decades has been steadily declining. In the process of studying in engineering specialties, students face difficulties in understanding subjects, performing group and individual tasks. This leads to poor grades, absenteeism and exclusion from the university. The tendency to reduce the number of classroom hours and a small number of hours for practical classes also contribute to the unpopularity of these specialities among young people in Ukraine. Therefore, scientists face an urgent need to find new teaching methods, the means of promoting motivation for learning, and the possibility of obtaining practical experience for students of engineering specialties in a higher educational institution. Among perspective directions of improving the pedagogical influence on students of engineering specialities, in our opinion, is extracurricular work.

This research is carried out within the framework of the scientific project "Integrated Model of Competitive Higher Education in Ukraine under the Quadruple Helix (Interdisciplinary) Concept", being implemented by a team of young scientists from Chernihiv National University of Technology from October 2017 to September 2020. The project is based on the concept of Knoster (1991) on the leadership and management of complex systems transformations in the form of a 6-component matrix (vision + consensus + skills + incentives + resources + action plan $=$ success of the reform) that was developed and used for reforming higher education systems in the USA and Great Britain. We suggest using this matrix as a horizontal framework for the modernisation of the higher educational system in Ukraine. The project 
implementation will include adaptation of the EU methodology for assessing the impact of policy tools on higher education, which will allow qualitative and quantitative assessment of the potential effects of applying a combination of regulatory instruments at the macro level (and compare regulatory options with European case studies).The hypothesis of the scientific project: a high-quality effective model of competitive higher education should combine social infrastructure, an effective mechanism for acquiring competences, leadership in providing educational services, a market mechanism for autonomous functioning of the institutions of higher education (IHE) and an effective system of budget financing, focused on the result. In this context, the need to improve approaches and methods of extracurricular work with the youth is made actual by bringing it in line with the best international practices in order to ensure the development of professional competences among higher education graduates and to increase their competitiveness in the national and global labour markets. Key vectors for the modernisation of extracurricular work with students are the promotion of academic integrity, the expansion of the principles of inclusion in higher education, the acceleration of academic mobility, the promotion of commercialisation of scientific developments and operational economic socialisation of future specialists in engineering specialties.

Taking into account all the above mentioned, the purpose of this article, based on the experience of implementation of the author's methodology of ALM at Tallinn University of Technology (Estonia), is to develop and test the preliminary results of implementation of the model of extracurricular work with students of engineering specialities at Chernihiv National University of Technology (Ukraine).

\section{Methods}

The following methods have been used for the observing stage of the experiment:

- theoretical - analysis, synthesis of pedagogical, socio-pedagogical, socio-psychological literature for determining the degree of development of the investigated scientific issue, generalisation in order to substantiate the essence of forming the motivation of students of engineering specialties to achieve success in studying in a higher education institution;

- empirical - questionnaire, testing, observation, oral questioning, interviews, analysis of the results of activity, which helped to identify the level of readiness of students of engineering specialities to participate in extracurricular work and their awareness of the forms and methods of extracurricular work;

- mathematical and statistical methods for quantitative and qualitative analysis of data obtained during the research process.

We developed the questionnaire, the purpose of which is to determine the attitude of students to extracurricular work and their willingness to participate in this type of activity. The suggested questionnaire is anonymous, consists of 14 questions: 4 general questions (for determining age, sex, specialty, course of study); 10 open and closed questions for determining the attitude of students to extracurricular work, their interest in this type of activity and determine their readiness to be a participant in various forms and methods of extracurricular work.

The following test methods have been used to determine professionally important skills: the methodology for determining the evaluation of communicative skills of Karelin (1999), the methodology for determining the motivation to succeed of Orlov (2018), the methodology for determining self-confidence estimation of Matsko, Pryshchak, \& Pervushyn (2018).

The participants of the research were students of the 3rd year of bachelor training (92 persons) in engineering specialties, namely: 123 - Computer engineering, 131 - Applied mechanics, 191 - Construction and civil engineering, 274 - Automobile transport. This study was conducted during 2017-2018.

\section{Results}

The process of training specialists in engineering specialities at a higher educational institution is quite complex and requires from students significant physical and intellectual efforts, personal responsibility (Blair \& Toder, 2016). After studying at school where students mostly have to master the material provided by the teacher, university studies in technical specialties for many students is an extremely challenging task. Therefore, starting from the first year, the number of students has been significantly reducing. This situation is very undesirable for Ukraine and other developed European countries, including Estonia.

We have been analysing the dynamics of the number of students of engineering specialities at Chernihiv National University of Technology during 2016-2018. We found that the number of full-time students studying in this specility has the highest rates of decreasing. For example, in groups that have been studying since 2016, the number of students who were expelled due to the academic debts is up to $25 \%$. If to compare with the corresponding groups of humanitarian specialties, the dynamics of the decrease of the community of students is only $3 \%$. 
In the course of personal interviews with students who stopped their studies in engineering specialities, it was discovered that among the reasons for failure, they outlined the complexity of the profession itself and academic disciplines, as well as the lack of sufficient classroom time for a deep understanding of the subject or a topic. In our opinion, under such conditions, one can use the potential of extracurricular work with students. Under extracurricular work, we understand the activity of students, in which they are engaged in the time free of classroom hours in a higher educational institution under the guidance and control of teachers in order to form a professional competence, as well as for self-actualisation, self-training and selfeducation (Detsiuk, 2014). Accordingly, extracurricular work with students is the organisation of training and educational activities based on an individual approach, that promote the acquisition of professionally important knowledge, development of skills, which is an integral part of vocational training and is carried out outside the schedule of training sessions.

In order to determine the attitude of students to extracurricular work, we conducted a questionnaire survey among representatives of the 3 rd year of engineering specialties. The total number of participants was 92 persons. We have received the following results:

Most students (69\%) consider the number of hours devoted to practice to be insufficient for acquiring the necessary professional experience. On the question "If you were invited to participate in a project on a volunteer basis, that would contribute to your professional growth, would you agree?", we received the following answers: yes $-44 \%$, probably $-49 \%$, no $-7 \%$. The experience of participating in the activities of clubs, other student associations or types of extracurricular activity at the university have $52 \%$ of the respondents, in the future $16 \%$ plan to get such experience, $12 \%$ did not know about such a possibility, for $20 \%$ such an opportunity is not interesting. This shows the readiness of the majority of respondents to participate in a qualitatively and interestingly organised extracurricular work.

Most students (82\%) believe that extracurricular work has an impact on the formation of the individual and on the professional growth of a future specialist. They note that extracurricular work influences selfconfidence building and communication skills development (40\%), the formation of professional knowledge and experience (17\%), leadership skills formation (8\%), and contributes to the search for new skills and abilities $(26 \%)$, team building skills formation $(9 \%)$. We have received the following answers to the question "What motivational methods, in your opinion, best contribute to the participation of students in extracurricular activities at the university?": internal motivation (self-development, self-improvement, professional growth) $-28 \%$, material incentives (bonuses, money rewards) $-37 \%$, educational incentives (bonuses in education, additional points) $-25 \%$, respect among others (photo on the board of worship, winning the competition) $-9 \%$. Such results give us the basis for determining the necessary pedagogical conditions that will motivate the participation of students in extracurricular work.

Respondents also noted that in order to succeed any person needs the following personal qualities: responsibility (24\%), purposefulness (23\%), creativity (20\%), communication skills (13\%), teamwork skills (16\%). So, based on these results, we invited the respondents to take part in the testing for assessing communicative skills, motivation to success and self-confidence. It turned out that $58 \%$ of respondents need to develop self-confidence, $36 \%$ feel confident enough, $6 \%$ are not quite confident. During assessment of communicative skills, we received the following results: $2 \%$ of respondents are bad interlocutors; $33 \%$ of respondents are not very good interlocutors who have shortcomings in communication; $60 \%$ have an average level of communication skills and only 5\% have excellent communication skills. The motivation for success among the majority of respondents (73\%) is average, in $16 \%$ of the respondents - too low, $4 \%$ - low, $5 \%-$ an extreme need for success, $4 \%$ - a high need for success.

\section{Discussion}

These results have once again confirmed the need to find new methods and forms for working with students. Proceeding from all of the above, we have developed a model of extracurricular work with students of engineering specialities. The basis of this model is the experience of two universities, namely the use of the author's methodology of ALM (active learning methods) at Tallinn University of Technology and the experience of extracurricular work with students at Chernihiv National University of Technology (Figure 1). The purpose of the model is to promote among students of engineering specialities the motivation towards success in learning. The main task for us is to increase the level of students' successfulness, to form their self-confidence, the feeling of being a part of a team.

One of the components of our model is the content. It includes scientific approaches, in the context of which there is work performed to increase the motivation towards achievement of success in learning among students of engineering specialities. These approaches are: systemic, personal, active and technological. 
Pedagogical conditions for the inclusion of students in the learning process make the content of the conditional component of the model. We have combined them into four interconnected blocks:

- Using ALM methodology in the process of professional training of students of engineering specialities;

- Integration of classroom and extracurricular work with students;

- Ensuring the motivation of students to participate in extracurricular work;

- Methodological support for organising and conducting extracurricular work with students of engineering specialities.

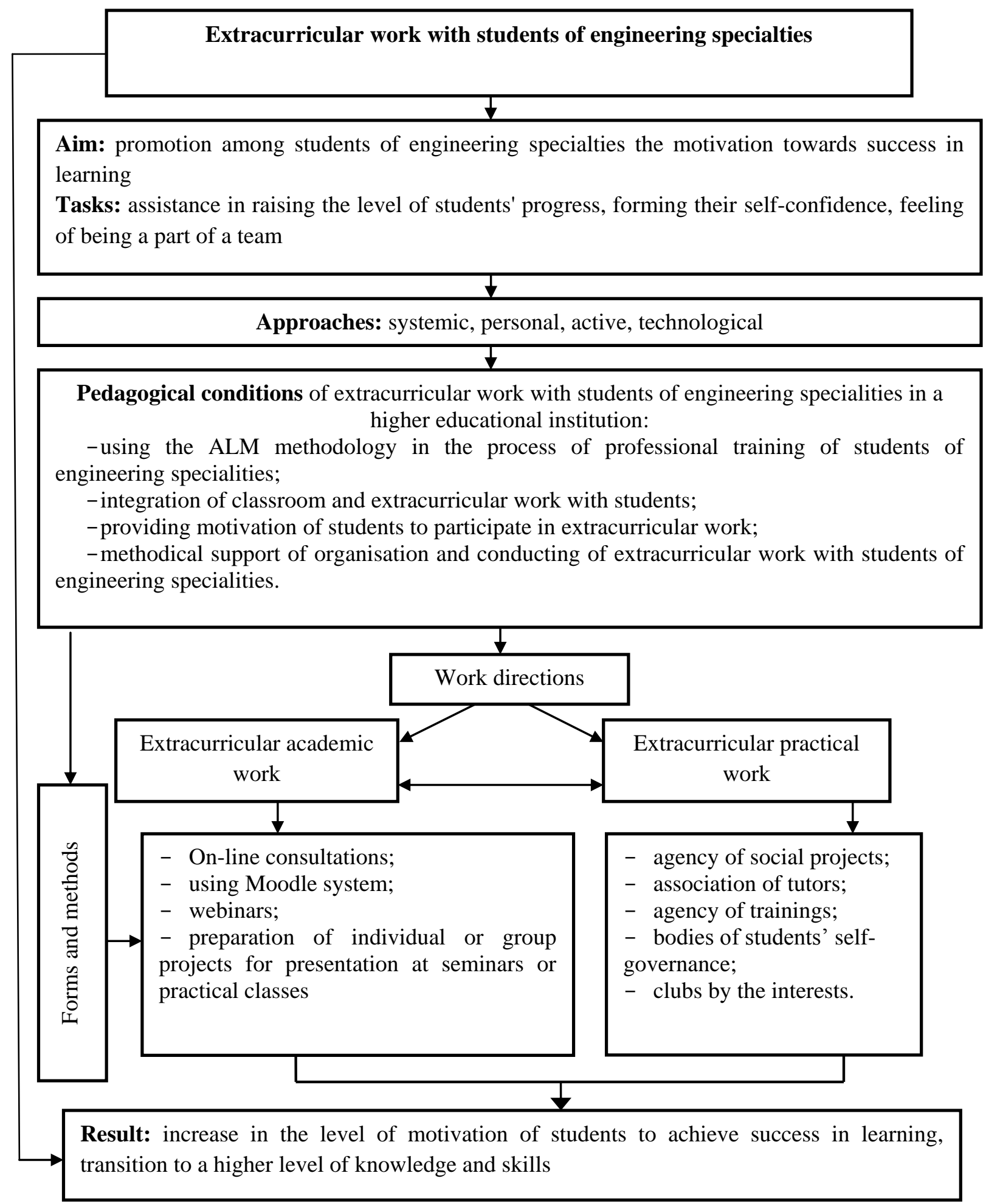

Figure 1. Model of extracurricular work with students of engineering specialties 
The model of extracurricular work with students of engineering specialities has an operational component, which includes directions, forms and methods. For the implementation of pedagogical conditions, we suggest working in two areas: extracurricular academic work and extracurricular practical work.

The first direction is realised through the forms and methods of extracurricular work, which directly relate to the learning process and the results of such work should be evaluated during the classroom studies, they should contribute to raising the level of education. The basis of this direction is the experience of applying the author's ALM (active learning method) methodology with students of engineering specialities, introduced at Tallinn University of Technology.

The author's ALM methodology with students at Tallinn University of Technology is a provision for teaching and training in English and Estonian, a convenient Internet environment for communicating with students, an original set of tools for design and a self-assessment system. The purpose of the introduction of this technique is to broaden the opportunities to obtain knowledge for different groups of students. The ALM methodology includes a combination of student-centred, inspirational, creative style of giving lectures, individual work, homework, teamwork and peer-to-peer approach.

The methodology of theoretical studies has been improved in such a way that the content of the course is divided into two components: compulsory and optional. Now all disciplines contain both traditional lectures and independent study material. Each lecture consists of the following four parts: a preliminary discussion of the preliminary material, a pre-lecture or post-lecture discussion, a teaching of a new topic of compulsory material, which may include a lecture discussion on correct/incorrect answers to the survey, as well as a post-lecture summary (Raud, Vodovozov, Aksionov, \& Petlenko, 2017, p. 2).

A combination of theory and practice, that is, classroom and extracurricular work (Omer Faruk Islim, 2017), the use of technical methods and tools (Hsieh \& Huang, 2014) is important for enhancing the process of forming professional competence among engineering students. During this training, in addition to the classical cooperation between students and teachers, there is also an interaction under the "studentstudent" scheme (Hsiung, 2012; Herrmann, 2013; Lin, 2015). Students in small groups or pairs accumulate ideas, discuss, and create a joint product in the form of certain projects, teaching each other. Obtaining a common positive result adds self-confidence, motivates to further education. In this process, the role of a teacher as a facilitator or supervisor is important, which can at any stage of project development join the working group and, if necessary, either support, or help, or direct in the right direction. The result is a technical report prepared by students.

The additional part of the classes contains a number of open issues (cases), designed in accordance with the topics in the curriculum. Each student can solve as many cases, as possible. Within the described learning environment, practice may occur along with lectures, or it can follow lectures, as well as precede them if necessary (Raud, Vodovozov, Aksionov, \& Petlienkov, 2017, p. 3).

To implement project training in the Master studies, the greatest part of the semester is focused on complex real issues. The engineering objective of the project is to create an effective system using the components offered by many global companies (Dim, 2004). Such an approach to project learning in the Master studies is extremely useful and necessary, in our opinion, for Ukrainian IHE, since it allows future specialists and faculty members to commercialise scientific achievements of students, establish close links with employers, gain practical experience, and the students - to feel themselves a part of the team, believe in their own strength.

Unfortunately, not all students demonstrate good results from using ALM. Part of the students, despite all the efforts, does not have time to accomplish all the tasks, to understand what is required, to complete the project, due to the features of temperament or intellectual abilities (Anderman, Austin, \& Johnson, 2002). However, there are some students who are deliberately unwilling to make efforts. In this regard, one of the main goals of academic counselling is to help them to study. This activity includes identifying students with academic issues, finding causes for issues and encouraging students to succeed.

The first step in working with such students is an understanding of the issue that prevents the student from obtaining knowledge and developing professional competence. This issue may lie in the student's unfavourable environment or his/her psychological or physical characteristics, habits and learning styles (Hsieh, Huang, 2014, p. 71). The aim of the teacher is to focus on the conceptual understanding of the issues being studied by identifying the parts that need to be explained again or simplified; to organise comfortable training conditions, to offer appropriate educational resources; allocate time to listen to students; not to allow students to switch attention to other things during the class and not allow them to just sit and watch in the classroom. Teachers are also encouraged to pay attention to any physical or mental characteristics of students and to use an individual approach, selecting the forms and methods of working with the student in accordance with his abilities and peculiarities. 
For most young people, online communication today is more interesting than personal communication (Rennie \& Morrison, 2013; Stavytska, 2017). According to the results of our study, the average number of chat messages exchanged between a student and a teacher ranged from 20 to 35 in the semester, which greatly exceeds the number of contacts in the audience. This approach fosters the feeling of success among students, promotes self-confidence and self-satisfaction. Those who actively use this opportunity are finally getting results from learning.

Taking into account, that encouragement plays an important role in the pursuit of success (Hsieh \& Huang, 2014), the transition from "one-time evaluation" to "continuous evaluation" has been done. The new evaluation scheme involves several evaluation steps in the time interval. A form-oriented approach is supported, which improves learning with the help of fast feedbacks due to the adapted to a student's level learning. The suggested evaluation procedure regularly monitors the student's success and can be used as a motivation for new achievements. In addition, it changes the student's consciousness, allowing using the assessment as an improvement tool (Lopez-Fernandez, Alarcón, \& Toar, 2015). Such an approach contributes to the integration of evaluation, teaching and training tasks, thus actively involving students in evaluating their own work and developing reflexive thinking. To facilitate the use of students of the Moodle information system, evaluation home pages have been developed and updated on a regular basis. When students successfully cope with the task, the evaluation system encourages them with complimentary words (Peng, 2004).

The second direction of realisation of pedagogical conditions of the model of extracurricular work with students of engineering specialities is aimed at the formation of practical skills, the formation of selfconfidence among students, a sense of being a part of the team. In our opinion, besides the well-known forms of extracurricular work such as student self-government bodies and clubs by the interests, modern innovative forms should be used. Among them, we have selected such as:

- Agency of social projects. In 2017, more than 100 students of the Mechanical and Technological Faculty and the Faculty of Construction Engineering of Chernihiv National University of Technology were involved in the creation and implementation of the project "Trash Art Places: Eco-Planet near the University", which was implemented with the financial support of the British Council. The main idea of this project was to create elements of urbanism (street benches, shelters, photo-zones, banners etc.) from the secondary raw materials. Students were given the opportunity to try themselves as professionals, to work in a team, to work with representatives of different specialties and faculties, to create their own small art projects, which then could be realised. As a continuation of this project was developped the project "Art-yard", aimed at formation of a creative area for outdoor recreation near the university's main building. Most participants (about $70 \%$ ) during the oral interview expressed their willingness to participate in writing and implementing of other projects;

- Agency of trainings. About 80 students of engineering specialties in the period of 2017-2018 became participants of 4 trainings "Active Citizens" under the programme of the British Council, as well as of the training "Principles and Values of Sustainable Development". Participants gave their feedback on the training during the survey, according to which $68 \%$ of respondents indicated that this experience contributed to the formation of teamwork skills; $72 \%$ - contributed to the formation of communicative skills; $55 \%$ increased the level of self-confidence.

- Association of tutors. As for tutors, we mean the association of individuals conducting individual or group classes with students, acting as tutors, mentors, supervisors. These are teacher's assistants, usually postgraduate students or senior students (Detsiuk, 2014).

The resulting component of the model involves specific outcomes of raising the level of motivation among students to achieve success in learning, moving to a higher level of knowledge and skills. Integration of practice and theory, change of pedagogical tactics and approaches, concentration of attention on students' motivation, individual approach to each student in our opinion will contribute to the reduction of the losses of the contingent of students of engineering specialities.

The preliminary results of approbation of the model are satisfactory and have demonstrated the prospect of further implementation of the model of extracurricular work with students of engineering specialities in the university's educational process. The suggested model has an integrated approach and needs further testing and validation. At the same time, we understand the need for its further improvement. In particular, we are talking about the addition of modern pedagogical instruments and techniques, for example, the use of causal methods (Shmatkov, 2016) and conceptual maps (Omer Farouk Islim, 2017), the application of interdisciplinary didactic methods (Shmatkov, 2016). In our opinion, special attention in extracurricular work with students of engineering specialities should be given to the development of their intellectual mobility as well as the integration of training and professional training (Mikhnenko \& Absalimova, 2018). 


\section{Conclusions}

According to the results of the study, it turned out that most students of engineering specialities require creation of additional conditions for training and formation of professional skills, such as communication skills. They also need additional conditions to shape the motivation to success and self-confidence. In addition, most students consider participation in extracurricular work important for their own professional growth, have shown interest in extracurricular work and willingness to become participants in its various forms and methods. In order to promote students' motivation to succeed in learning, a model of extracurricular work with students of engineering specialities has been developed. The first stage of the implementation of this model has shown a positive dynamics. The model requires further testing and research of the impact on the students'personality.

\section{Acknowledgement}

This research is carried out within the framework of the scientific project "Integrated Model of Competitive Higher Education in Ukraine under the Quadruple Helix Concept" with the support of the Ministry of Education and Science of Ukraine. We would like to express our gratitude to the project leader N.I. Kholiavko for her assistance and commitment.

\section{References:}

Anderman, E.M., C.C. Austin, \& Johnson, D.M. (2002). The development of goal orientation. In Wigfield, A. \& Eccles, J.S. (Eds.). The Development of Achievement Motivation (pp.197-220). NY, USA: New York Academy Press. https://doi.org/10.1016/b978-012750053-9/50010-3

Blaj, C. \& Toader, D. (2016). Bologna process not (yet?) a success for electric and electronic engineering at UPT, International Symposium on Fundamentals of Electrical Engineering (ISFEE), Bucharest, Romania, 1-5. Retrieved August, 11, 2017, from https://ieeexplore.ieee.org/stamp/stamp.jsp?arnumber=7803148

Detsiuk, T.M. (2014). School of tutors as a condition for the formation of professional competence. Bulletin of Cherkasy University. Series: pedagogical sciences, 30 (323), 60-65. Retrieved July, 4, 2018, from https://www.ir.stu.cn.ua/Detsiuk

Dym, C.L. (2004). Design, systems, and engineering education. International Journal of Engineering Education, 20 (3), $305-312$.

Herrmann, K. J. (2013). The impact of cooperative learning on student engagement: Results from an intervention. Active Learning in Higher Education, 14(3), 175-187. https://doi.org/10.1177/1469787413498035

Hsieh, T. H. \& Huang, H. C. (2014). Happy studying by gamificational role playing. International Conference on Orange Technologies. Hian, China, 69-72. Retrieved August 2, 2017, from https://ieeexplore.ieee.org/xpl/mostRecentIssue.jsp?punumber=6942527

Hsiung, C. M. (2012). The effectiveness of cooperative learning. Journal of Engineering Education, 101(1), 119137. https://doi.org/10.1002/j.2168-9830.2012.tb00044.x

Islim, O.F. (2017). Technology-supported collaborative concept maps in classrooms. Active Learning in Higher Education, 19 (2), 131-143. https://doi.org/10.1177/1469787417723231

Lin, L. (2015). Investigating Chinese HE EFL classrooms: Using collaborative learning to enhance learning. Springer, Berlin, Heidelberg. https://doi.org/10.1007/978-3-662-44503-7

Karelin, A. (1999). Test assess communication skills. Technological tests. Moscow, Russia: Vologda Regional Universal Scientific Library. Retrieved May 13, 2018, from https://www.booksite.ru/fulltext/tes/ty2/psy/hol/ogy/2.htm

Knoster, T. (1991). Leading and Managing Complex Change. Retrieved June, 12, 2017, from https://www.ocde.us/Administrative/H R/Documents/OCDE\%20Academy/Leading\%20and\%20Managing\%20Complex\%20Change.pdf

Lopez-Fernandez, D., Alarcon, P. \& Tovar, E. (2015). Motivation in engineering education. A framework supported by evaluation instruments and enhancement resources, IEEE Global Engineering Education Conference (EDUCON), Tallinn, Estonia, 421-430. Retrieved June, 21, 2017, from https://www.researchgate.net/conference-event/EDUCON_IEEE-GlobalEngineering-Education-Conference_2015/12016

Matsko, L., Pryshchak, M. \& Pervushyn, T. (2018) Fundamentals of psychology and pedagogy. Laboratory Workshop. Retrieved May, 13, 2018, from https://posibnyky.vntu.edu.ua/opp/19.html

Mikhnenko, G. \& Absaliamova, Y. (2018) The formation of intellectual mobility of engineering students through integration of foreign language education and professional training. Advanced Education, 9, 33-38. https://doi.org/10.20535/24108286.121057

Orlov, Yu.M. (2018) Test - questionnaire need to achieve the goal. A scale for assessing the need for success. Psychology of happy life. Retrieved May, 13, 2018, from https://psycabi.net/testy/475-metodika-orlova-yu-m-test-oprosnik-potrebnost-vdostizhenii-tseli-shkala-otsenki-potrebnosti-v-dostizhenii-uspekha

Raud, Z., Vodovozov, V., Aksjonov, A. \& Petlencov, E. (2017). Promotion of the Students' Succes in Higher Engineering Education. 58th International Scientific Conference on Power and Electrical Engineering of Riga Technical University (RTUCON). Retrieved August, 4, 2018, from https://ieeexplore.ieee.org/document/8124806/

Rennie, F., \& Morrison, T. (2013). E-learning and social networking handbook: Resources for higher education. Routledge. https://doi.org/10.4324/9780203120279

Shmatkov, D. (2016) The use of causal maps as interdisciplinary didactic reduction method. Advanced Education, 6, 16-21. https://doi.org/10.20535/2410-8286.74335

Stavytska, I. (2017) The formation of foreign language competence of engineering students by means of multimedia. Advanced Education, 7, 123-128. https://doi.org/10.20535/2410-8286.95301 